\title{
Integration of Digital Dentistry into a Predoctoral Implant Program: Program Description, Rationale, and Utilization Trends
}

\author{
Fatemeh S. Afshari, DMD, MS; Cortino Sukotjo, DDS, MMSc, PhD; Maria F. Alfaro, DDS; \\ Jeri McCombs, DDS; Stephen D. Campbell, DDS, MMSc; Kent L. Knoernschild, DMD, \\ MS; Judy Chia-Chun Yuan, DDS, MS
}

\begin{abstract}
A recently revised predoctoral implant curriculum at the University of Illinois at Chicago College of Dentistry integrated digital dentistry into both the preclinical dental implant course and clinical activities. Traditionally, competence in the didactic and clinical parts of predoctoral education in single tooth implant restorations has emphasized the analog impression technique and subsequent mounting of soft tissue working casts. However, computer-aided design/computer-aided manufacturing (CAD/ CAM) implant restorations can play a significant role in predoctoral dental education utilizing digital technologies. The goal of the curriculum expansion is to transition from analog to partially digital and, finally, complete digital workflow. The aim of this article is to describe the specific components, implementation, and rationale for the new digitally integrated implant curriculum and present short-term clinical utilization trends.
\end{abstract}

\begin{abstract}
Dr. Afshari is Clinical Associate Professor, Department of Restorative Dentistry, College of Dentistry, University of Illinois at Chicago; Dr. Sukotjo is Associate Professor, Department of Restorative Dentistry, College of Dentistry, University of Illinois at Chicago; Dr. Alfaro is a prosthodontics resident, Department of Biological and Materials Sciences and Division of Prosthodontics, School of Dentistry, University of Michigan; Dr. McCombs is a dental graduate of the College of Dentistry, University of Illinois at Chicago; Dr. Campbell is Professor and Head, Department of Restorative Dentistry, College of Dentistry, University of Illinois at Chicago; Dr. Knoernschild is Professor and Program Director of Advanced Prosthodontics, Department of Restorative Dentistry, College of Dentistry, University of Illinois at Chicago; and Dr. Yuan is Associate Professor and Predoctoral Implant Program Director, Department of Restorative Dentistry, College of Dentistry, University of Illinois at Chicago. Direct correspondence to Dr. Judy Chia-Chun Yuan, Department of Restorative Dentistry, College of Dentistry, University of Illinois at Chicago, 801 S. Paulina Street, Chicago, IL 60612; 312-355-4027; yuanjudy@uic.edu.
\end{abstract}

Keywords: dental education, dental implant, digital dentistry, educational methodologies, educational technologies, CAD/CAM

Submitted for publication 8/26/16; accepted 12/26/16

doi: 10.21815/JDE.017.050

$\mathrm{M}$ ore than 20 years ago, the first commercially viable computer-assisted design and manufacturing (CAD/CAM) system was introduced to the dental profession. Chairside $\mathrm{CAD} /$ CAM systems typically consist of three main components: 1) a chairside optical scanner that captures the geometry of a prepared tooth, transforming it into three-dimensional digital data; 2) computer software that allows the user to design a dental prosthesis; and 3 ) an additive or subtractive manufacturing process that transforms the data into a final prosthesis. ${ }^{1-3}$ $\mathrm{CAD} / \mathrm{CAM}$ technology combined with advances in material technology allows for a reduction in labor, reduced clinical and laboratory work steps, ${ }^{4}$ and reduced treatment cost. ${ }^{5}$ These efficiencies support cost-effectiveness with savings estimated at $60 \%$ to $70 \%$, along with better quality control and improved patient experiences. ${ }^{2,3}$ This breakthrough technology thus holds the potential to profoundly impact the future of oral health care and revolutionize dentistry.

The use of CAD/CAM systems in dentistry has increased as new materials and improved hardware and software have been introduced to the market. In 2011, Davidowitz and Kotick estimated that 10,000 units were being used in North America, which translates to $15 \%$ of dental practices in the U.S. ${ }^{2}$ In that year, according to Davidowitz and Kotick, William Blair and Company estimated that sales would 
further expand with an increase of 9,100 units per year as of 2017. Nevertheless, the adoption of this revolutionizing technology has been gradual. In U.S. dental schools, training in CAD/CAM indirect restorations occurs in a majority of preclinical didactic settings $(76 \%)$, but only about half of responding schools reported incorporating it in the preclinical laboratory and clinical patient experience ${ }^{6}$ However, both students and faculty members have expressed enthusiasm and given positive feedback regarding learning about and using this technology. ${ }^{7,8}$

In light of Iacopino's observation that most new practitioners use technologies they were exposed to in their dental training, ${ }^{9}$ the University of Illinois at Chicago College of Dentistry introduced CAD/CAM technologies to its four-year predoctoral curriculum. Since 2014, the college has used CAD/CAM technology in both its predoctoral and postdoctoral student clinics, so that graduates are competent in providing both tooth- and implant-supported digital restorations. The college introduced a competency statement with learning objectives, acquired multiple hardware and software units, trained the faculty, employed a digital design technician (DDT), and established a digital center that consists of a training center and a centralized clinic that allow for in-house fabrication of provisionals and all-ceramic inlays, onlays, single crowns, veneers, and fixed dental prostheses.

Traditionally, digital dentistry relative to dental implants focused more on the surgical placement of the implant. ${ }^{10}$ On the other hand, most predoctoral implant clinical curricula focus on the restorative aspect. ${ }^{11}$ Today, digital technologies can be incorporated and taught as part of implant planning and restoration. The University of Illinois at Chicago College of Dentistry has incorporated digital dentistry as an integral part of the predoctoral implant program as it potentially provides significant advantages in time efficiency and esthetics over traditional crown fabrication procedures. Patient experiences may be transformed relative to comfort and time as digital technologies have been found to be patient-preferred. ${ }^{12}$ Student education may be further enhanced relative to assessment, diagnosis, treatment planning, and treatment of patients who require single tooth implant-supported restorations. As today's patients are more knowledgeable about dental technologies and seek state-of-the-science dental care, graduating practitioners must be properly trained. The millennial generation of dental students quickly adapt and frequently use emerging technology, so exposing them to digital dentistry will better prepare them for the future. ${ }^{13,14}$ The aim of this article is to describe the specific components, implementation, and rationale for the new digitally integrated implant curriculum and present short-term clinical utilization trends.

\section{Key Components of the Implant Curriculum}

Descriptions of the college's predoctoral implant program, competency categories, pedagogies, and assessments for implant-supported, single unit digital restorations have been previously published ${ }^{15-17}$ and are summarized in Table 1. Briefly, the predoctoral implant curriculum starts in the spring semester (beginning in January) of the second year. Approximately 104 students participate in the pre-patient didactic and hands-on laboratory sessions. During this four-month period, they receive an extensive 24 hours of lectures presented by multidisciplinary faculty members, followed by 30.5 hours of pre-patient laboratory exercises. In the third year, students matriculate into the clinic for implant patient care until graduation. The competency, teaching pedagogy, and assessment tools vary based on the year. Digital implant dentistry instruction is integrated into the core implant curriculum, which consists of lectures and hands-on preclinical and clinical experiences.

\section{Assessment and Learning Objectives}

Formal competency statements, learning objectives, and performance exams were established for implant-supported, single unit digital restorations. The competency statement reads: "Students must be competent in the assessment, diagnosis, treatment planning, and application of digital technologies with implant-supported single unit restorations for partially edentulous patients." The intent is for students to receive the instruction and experience necessary to become competent in providing care using digital technologies to restore single tooth implants (STIs). Students should also be able to describe available digital techniques for single unit restorations, collaborate with a DDT for these types of restorations, and properly implement the referral process for more complex patient scenarios. At the end of their clinical training, all students are expected to complete their first implant-supported restorations using the conventional or analog approach via 
a partial digital workflow and all other restorations using the complete digital workflow. Furthermore, a performance exam has been formulated for intraoral scanning of implant fixtures followed by fabrication and delivery of a custom abutment and all-ceramic restoration. This exam will ensure that students are competent in providing single tooth implant digital restorations.

Table 1. Competency category, pedagogy, and assesment for implant-supported single unit digital restorations

\begin{tabular}{|c|c|c|c|}
\hline Class & Competency Category & Pedagogy & Assessment \\
\hline \multirow{17}{*}{$\begin{array}{l}\text { Second-year } \\
\text { dental students }\end{array}$} & \multirow{9}{*}{$\begin{array}{l}\text { Assessment, diagnosis, } \\
\text { treatment planning }\end{array}$} & Lectures & Quizzes \\
\hline & & Digital technology & Written exam \\
\hline & & $\begin{array}{l}\text { Intraoral/lab-based scan, custom } \\
\text { abutment, CAD/CAM crown, } \\
\text { workflow }\end{array}$ & \\
\hline & & Small-group learning & Written exam \\
\hline & & & Student collaborative group assessment \\
\hline & & & Faculty evaluation (criteria-based) \\
\hline & & & Treatment planning blog entry \\
\hline & & Clinical rotations & Self-reflections \\
\hline & & EBD projects & EBD reports \\
\hline & \multirow[t]{3}{*}{ Application } & Laboratory sessions & Laboratory session: project \\
\hline & & Digital technology & Station exams \\
\hline & & Hands-on STI scanning & \\
\hline & \multirow[t]{5}{*}{ Self-assessment } & Small-group learning & Self-reflections \\
\hline & & EBD projects & Self-evaluation \\
\hline & & Laboratory sessions & Self-evaluation \\
\hline & & Digital technology & \\
\hline & & Hands-on STI scanning & \\
\hline \multirow{12}{*}{$\begin{array}{l}\text { Third-year } \\
\text { dental students }\end{array}$} & \multirow{5}{*}{$\begin{array}{l}\text { Assessment, diagnosis, } \\
\text { treatment planning }\end{array}$} & Clinical patient care & Post-performance assessment \\
\hline & & Digital technology & Faculty and student verbal interactions \\
\hline & & Small-group learning & Written exam \\
\hline & & & Online quizzes \\
\hline & & & Faculty evaluation (criteria-based) \\
\hline & \multirow[t]{3}{*}{ Application } & Clinical patient care & Post-performance assessments \\
\hline & & Digital technology & Faculty and student verbal interactions \\
\hline & & $\begin{array}{l}\text { Intraoral scanning, custom } \\
\text { abutment, CAD/CAM crown }\end{array}$ & \\
\hline & \multirow[t]{2}{*}{ Performance exam } & Clinical patient care & Performance exam \\
\hline & & OSCE & Case-based exam \\
\hline & \multirow[t]{2}{*}{ Self-assessment } & Clinical patient care & Post-performance assessments \\
\hline & & & Faculty and student verbal interactions \\
\hline \multirow[t]{8}{*}{$\begin{array}{l}\text { Fourth-year } \\
\text { dental students }\end{array}$} & $\begin{array}{l}\text { Assessment, diagnosis, } \\
\text { treatment planning }\end{array}$ & Clinical patient care & Post-performance assessments \\
\hline & \multirow[t]{3}{*}{ Application } & Clinical patient care & Post-performance assessments \\
\hline & & Digital technology & Faculty and student verbal interactions \\
\hline & & $\begin{array}{l}\text { Intraoral scanning, custom } \\
\text { abutment, CAD/CAM crown }\end{array}$ & \\
\hline & \multirow[t]{3}{*}{ Performance exam } & Clinical patient care & Performance exam \\
\hline & & & Portfolios \\
\hline & & OSCE & Case-based exam \\
\hline & Self-assessment & $\begin{array}{l}\text { Clinical patient care } \\
\text { Portfolios }\end{array}$ & $\begin{array}{l}\text { Post-performance assessments } \\
\text { Self-reflections }\end{array}$ \\
\hline
\end{tabular}

Note: Each class consists of 52 DMD students and 52 advanced standing students. Boldface indicates elements in the digital curriculum.

STI=single tooth implant 


\section{Pre-Patient Component}

The pre-patient component in implant therapy incorporates didactic and hands-on laboratory sessions to properly prepare students for their patient experiences. With the introduction of digital technologies into the curriculum, additional didactic courses relative to the digital workflow and material have been added in multiple areas of the curriculum. Students receive hands-on training in scanning, designing, milling, and finalizing single unit toothsupported restorations on a typodont (Planmeca E4D Technologies, Richardson, TX, USA). To enhance active learning, training in intraoral scanning occurs in a small group setting with a faculty to student ratio of 1:6 in a dedicated Center for Digital Excellence (CDE). The CDE houses state-of-the-art computers, large display monitors, and video recording technology. Students also observe intraoral scanning (Trios3, 3Shape A/S, Copenhagen, Denmark) of an implant in a live patient in the implant clinic with a faculty to student to patient ratio of $1: 12: 1$. Relative to the lab-based scanning experience (3Shape and Dental Wings, Montreal, Canada), students have the opportunity to observe the digital workflow through prerecorded videos uploaded to an Internet-based platform (Blackboard, Inc., Washington, DC, USA).

\section{Clinical Component}

The predoctoral implant program is in a dedicated clinic with a select group of prosthodontic faculty members who supervise all phases of the implant therapy except the surgical procedures. These supervising faculty members approve patient selection, assist students with intraoral scanning, approve the custom abutment and restoration design, and authorize CAD/CAM milling of the definitive prosthesis. The DDT assists with all CAD/CAM fabrication steps, including intraoral and lab-based scanning, custom abutment order, restoration design, milling, crystallization, and characterization. The majority of the definitive prostheses are cementretained restorations. Screw-retained prostheses are selected for scenarios with challenging implant positions and restorative spaces. Indications and contraindications for definitive all-ceramic restorations are defined. Exclusion criteria are second molar site, patient with para-functional habits, or unstable occlusal contacts.

In the program, all-ceramic STI restorations can be fabricated via three routes: 1) analog workflow, 2) partial digital workflow, and 3) complete digital workflow (Figure 1). The goal of this expanded curriculum is to transition from analog to partially digital and finally complete digital workflow. The analog approach incorporates a fixture-level impression with an impression coping and elastomeric impression material, pouring and articulation of casts, and placing an order for a custom abutment via a commercial laboratory. Following the abutment try-in appointment, the articulated casts and abutment are sent to a laboratory for conventional crown fabrication. At the cementation appointments, the restoration is fitted, occlusal and interproximal contacts adjusted, and the crown cemented. This approach is used mainly for porcelain fused to metal and full cast gold restorations.

The partial digital workflow incorporates a fixture-level impression with an impression coping and elastomeric impression material. Students pour and articulate the casts as usual; however, instead of sending the casts to a commercial laboratory, a lab-based scan of the casts is completed by the DDT. The 3D digital file is then uploaded to the abutment manufacturer for a virtually designed custom abutment (VAD). The 3D file includes the virtual images of the casts including the implant site information. The predesigned, site-specific abutment can then be modified by the provider using an online editor tool. At our institution, the file is reviewed and approved by the faculty member and student together. Once the abutment is verified intraorally, the abutment $3 \mathrm{D}$ data file or core file is requested and used to design and mill the final ceramic restoration. Any subsequent modifications to the custom abutment necessitate a lab-based scan of the physical abutment on the working cast.

The complete digital workflow includes intraoral implant-level scanning with an intraoral scan body (Atlantis IO Flo; Dentsply Sirona, York, PA, USA). ${ }^{18}$ After evaluation of tissue health, the student is instructed to replace the healing abutment intraorally with a scan body and to radiographically verify the seating. Three scans are then completed with a Trios 3 intraoral scanner: 1) the scan body and adjacent teeth, 2) the opposing arch, and 3) an occlusal bite. If any discrepancies are noted, only the designated area is rescanned. The scans are then sent to the DDT for scan body orientation and abutment order, which occurs on the same day. The digital file is uploaded to the abutment manufacturer for a VAD. Faculty members approve the abutment design with the students, and the final abutment arrives within two to three working days. 


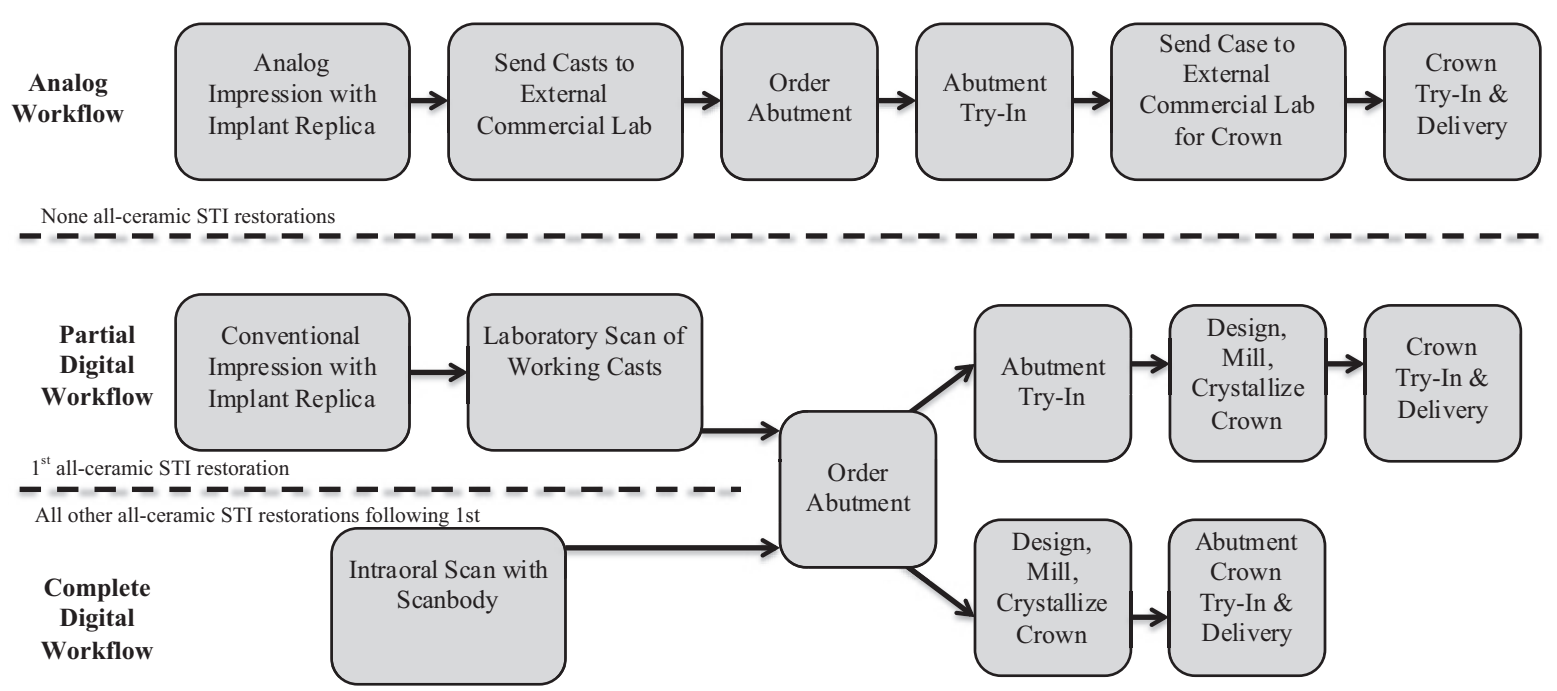

Figure 1. Predoctoral implant program showing analog, partial digital, and complete digital workflows for fabricating implant-supported definitive restorations

STI=single tooth implant

This workflow eliminates the need for elastomeric impressions, pouring of casts, articulation of working casts, and shipping, thus saving time and material. The final restoration is fabricated following the abutment try-in appointment. Typically, this process requires two separate clinical appointments; however, with proper pre-planning, it can be accomplished easily over two consecutive days or in a single day. The final restoration is designed and fabricated on the abutment 3D file unless modifications have been made to the abutment chairside. Likewise, in many situations the abutment 3D digital file can be used to design and mill the final ceramic restoration before the return of the physical abutment. This option allows for a single appointment delivery of the abutment and final ceramic crown. This process requires the application of well-established abutment design principles that may protect the implant-bone interface and ensure the crown-abutment interface is apical to the tissue crest while allowing for ease in access cement removal upon cementation.

\section{Rationale for the Program}

The current Commission on Dental Accreditation (CODA) predoctoral accreditation standards have minimal reference to knowledge and application of digital dentistry and technology as they relate to diagnosis, treatment planning, design, and application for the restoration and replacement of missing teeth. ${ }^{19}$ There are no "Must" statements related to these concepts. Technology is mentioned in the preamble of the document: "Technology enables dental education programs to improve patient care and to revolutionize all aspects of the curriculum, from didactic courses to clinical instruction." This statement is mostly directed towards learning technologies and electronic health records and is not related to patient care using digital technologies. There are several potential areas in the primary clinical Standard 2-23 in which digital dentistry can be applied. These are patient assessment, diagnosis, and treatment planning; communication with dental laboratories; replacement of teeth with fixed, removable, and implant therapies; hard and soft tissue surgery; malocclusion and space management; and recall and outcome strategies. Digital technology is currently mentioned in the 2-23 intent statement: "Graduates should be able to evaluate, assess, and apply current and emerging science and technology." However, this statement only offers guidance for educational programs and is not a requirement. In the future, modifications to the CODA standards seem warranted to promote evolving best practice principles for educational programs. 
As the number of fixed dental prostheses increases with intraoral digital impression technology, ${ }^{20}$ the advantages of CAD/CAM technology have become more apparent. As the dental profession rapidly gravitates towards the digital workflow to realize these benefits, it is imperative that dental schools give future practitioners adequate training to understand and apply digital technologies. The gold standard for final impression-making of dental implants has traditionally been a conventional impression via an open or closed tray technique. ${ }^{21}$ However, the traditional technique also has many time-consuming drawbacks, such as dimensional stability, deformation, and precision of impression materials,${ }^{22}$ the application of gypsum materials (stone casts), die trimming, and dental waxes. ${ }^{23-25}$

Digital technologies help eliminate these shortcomings and offer the clinician control over the final restoration that has historically rested with the dental laboratory. In vitro studies have found that direct scanning of dental implants was at least as precise as the conventional impression technique using impression copings ${ }^{26,27}$ although another study reported better fit of the final prosthesis for direct digitization as opposed to indirect digitization using conventional impression techniques. ${ }^{28} \mathrm{~A}$ recent randomized clinical trial found no statistically significant difference between the two techniques and a statistically significant positive result for occlusal contact with the digital impression. ${ }^{29}$ These findings may be a result of the interocclusal registration being completed with a buccal scan of teeth in occlusion as opposed to a registration material that can have inherent inaccuracies and lead to improper articulation of casts. In an educational curriculum, in which responsibility falls on students to pour final impressions in a timely fashion, using accurate water to powder ratios and mixing techniques, ensuring adequate die trimming, and properly articulating casts, the elimination of these steps via intraoral scanning can save time and reduce overall costs, as well as improve learning, faculty control, and outcomes.

Relative to clinical chair time, five recent studies assessing STI impression techniques found that digital processes were less time-consuming, ${ }^{12,29-32}$ while one study reported that patients perceived the duration of the intraoral scan more negatively than the conventional impression technique. ${ }^{33}$ This discrepancy relative to time is most likely dependent on the intraoral scanner and digital system. However, one can argue that, with a scanner, a clinician can easily rescan missing or unacceptable areas of the digital impression; but with a conventional impression, any missing information would necessitate a remake of the impression. A survey of dental technicians found that low quality impressions along with insufficient preparations were the greatest obstacles in fabricating an ideal restoration. ${ }^{34}$ Lee and Gallucci also reported that, among second-year dental students, conventional impressions necessitated longer preparation, working, and remake time in addition to requiring more experience to achieve the same level of proficiency. ${ }^{32}$ In a predoctoral setting, impression remakes occur often, as students have not fully mastered the impression procedure. Thus, chair time and material consumption should be minimized if possible. In addition, the application of intraoral scan bodies for the capture of implant position using digital scanning greatly simplifies the chairside technique and all but ensures a quick and accurate digital capture when compared to the subgingival margins associated with tooth preparations. This improvement makes this technology particularly applicable to ease of learning and application for STI. Therefore, we highly recommend the application of digital impression in predoctoral implant curricula.

Recently, Wismeijer et al. found that patients' overall preference was significantly in favor of intraoral scanning as opposed to the conventional impression technique. ${ }^{33}$ This finding was mainly due to the perception of taste of the impression material as well as the preparation process. Another study also found an increase in patient comfort and acceptance with digital technologies. ${ }^{12}$ A recent randomized clinical trial reported patient assessment of discomfort and dentist assessment of difficulty with the procedure to be low with intraoral scan as opposed to conventional impressions. ${ }^{29}$ All of these patient benefits may be a result of reduced procedure time, less likelihood of gagging and breathing difficulty, decreased discomfort for those with a limited opening, and sensitivity that may be caused by the impression material. ${ }^{12,29}$ Dental students also have shown a preference for digital impression making as opposed to the conventional technique. ${ }^{32}$

Finally, there are a myriad of learning opportunities for predoctoral students as crowns fabricated in-house can be evaluated in the design and production phase. Direct three-dimensional feedback on a magnified computer screen following intraoral scanning may help students assess the implant restorative space, depth of implant interface, and emergence profile. ${ }^{10}$ In our program, interested students are encouraged to work with the DDT at any phase of 
the process to learn more about digital technologies and restoration design principles. If deemed necessary, students can try-in the pre-crystallized implantsupported restoration and modify the contours and interproximal and occlusal contacts. Finally, with the patient and instructor's input, students can customize the final prosthesis as opposed to merely accepting what is returned from a commercial lab. This process will not only enhance student learning but also result in an improved outcome and patient satisfaction.

\section{Utilization Trends}

Over the past three years, the college has fully embraced teaching predoctoral students varying aspects of digital dentistry for implant-supported single unit restorations. The curriculum is based on a sound competency statement and learning objectives that resonate throughout the students' four years of dental education. To investigate clinical trends resulting from the integration of digital dentistry into the program, a chart review of all patients treated with STIs was conducted for the five quarters in the period from June 1, 2015, to August 31, 2016. The University of Illinois at Chicago's Institutional Review
Board approved that study (Protocol \#2015-0554). The number of patients receiving custom abutments via the analog workflow was recorded and compared to those receiving abutments via the partial and complete digital workflow. The numbers of patients receiving a $\mathrm{CAD} / \mathrm{CAM}$ ceramic restoration made in-house versus a full cast gold or porcelain fused to metal crown fabricated by an outside, commercial laboratory were also recorded and compared.

There was an observable trend in the number of STI restorations completed traditionally via analog impression and commercial laboratory versus in-house using digital technologies. Relative to the custom abutments, there was a steady rise in the number of custom abutments fabricated via intraoral and lab-based scanning (Figure 2). The percentage of digital abutments increased from 0 in the first quarter $(\mathrm{Q} 1)$ to $10.8 \%(\mathrm{Q} 2)$ to $8.7 \%(\mathrm{Q} 3)$ to $23.4 \%$ (Q4) to finally $83.3 \%$ in the final quarter (Q5). The percentage abruptly increased by the last quarter to the majority of the abutments ordered. A similar trend was also observed in the production of e.max $\mathrm{CAD} /$ CAM ceramic crowns $(12.5 \% \mathrm{Q} 1,21.6 \% \mathrm{Q} 2,18.2 \%$ Q3, 35.4\% Q4, 75\% Q5; Figure 3).

Full implementation has led to an observable increase in the number of STI custom abutments

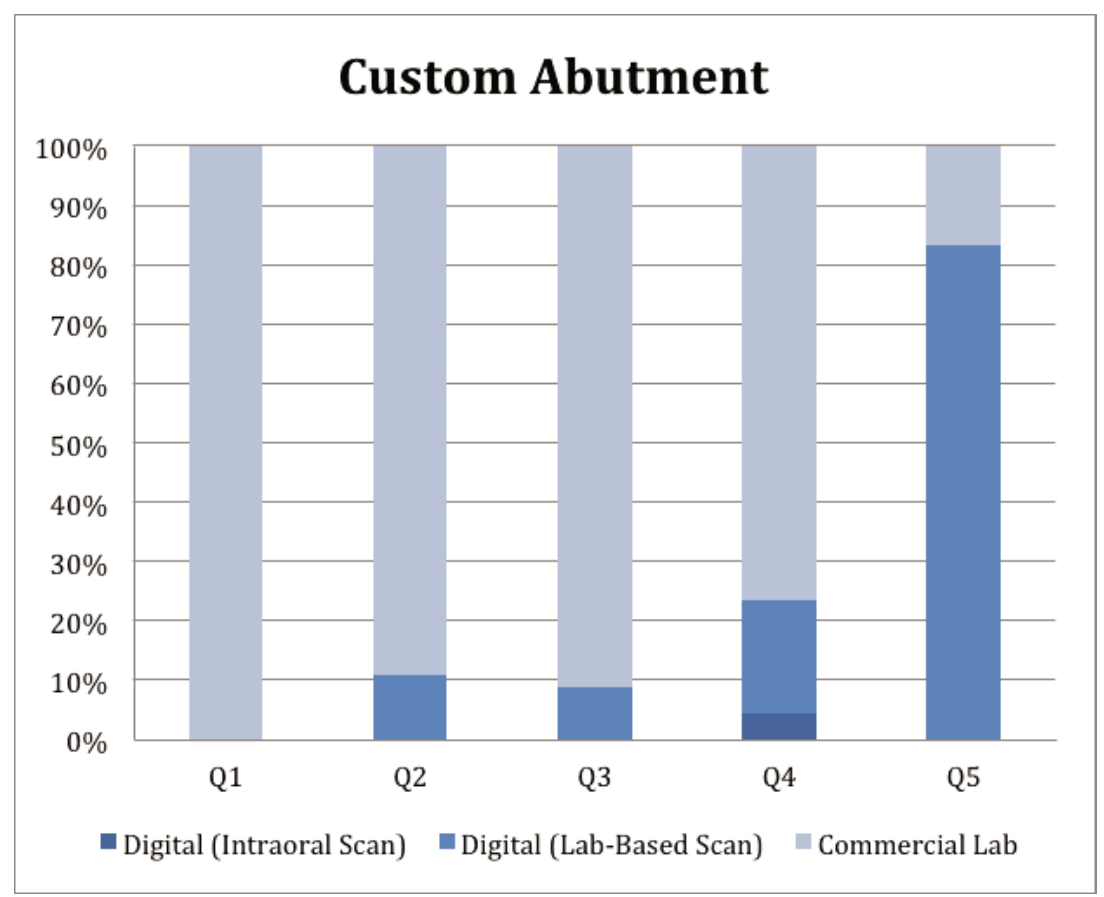

Figure 2. Total percentage of custom abutments delivered per quarter $(Q)$ using an intraoral scan, lab-based scan, or commercial lab (analog workflow), across five quarters from June 1, 2015, to August 31, 2016 


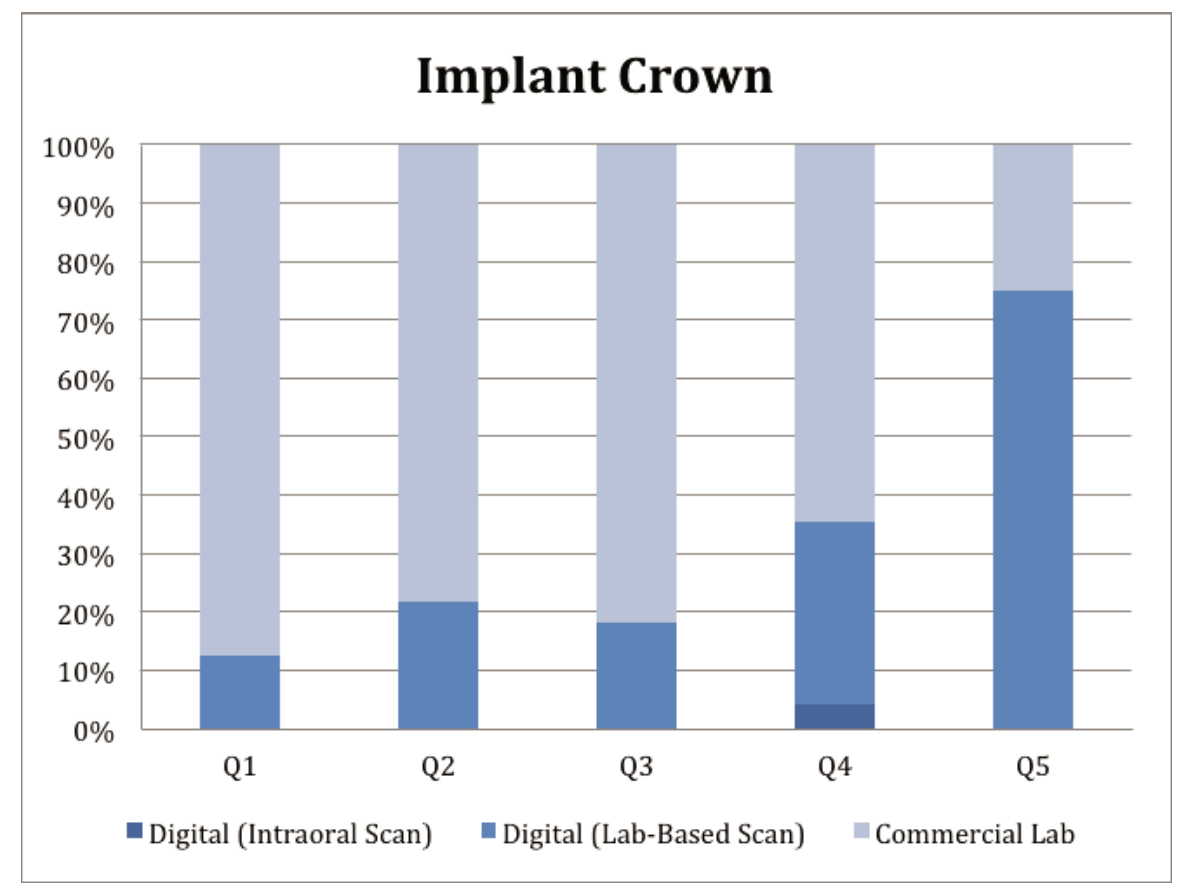

Figure 3. Total percentage of implant-supported definitive restorations delivered per quarter (Q) using an intraoral scan, lab-based scan (e.max ceramic), or commercial lab (analog workflow), across five quarters from June 1, 2015, to August 31, 2016

and definitive restorations fabricated in-house using CAD/CAM technologies. The goal of this program is to apply a complete digital workflow in the future. However, significant lead-time is required to establish faculty expertise, facilities, accumulation of the requisite technologies, IT integration, development of requisite learning objectives and competencies, and integration into the pre-patient care curriculum before broad application and clinical learning can occur. There exists an even slower trend in completion of intraoral scans, mainly due to the fact that the curriculum emphasizes student education in both analog impression technique and the fully digital approach.

\section{Conclusion}

This article presents a description and rationale of the implementation of CAD/CAM technologies in the University of Illinois at Chicago College of Dentistry's predoctoral implant program. Based on preliminary data, an observable increase in the proportion of implant restorations fabricated digitally as opposed to traditionally was noted. These preliminary data may serve as a model relative to implementation for other institutions in the process of adopting digital technologies for their educational and patient care programs.

\section{REFERENCES}

1. Beuer F, Schweiger J, Edelhoff D. Digital dentistry: an overview of recent developments for CAD/CAM generated restorations. Br Dent J 2008;204:505-11.

2. Davidowitz G, Kotick PG. The use of CAD/CAM in dentistry. Dent Clin North Am 2011;55:559-70.

3. Miyazaki T, Hotta Y. CAD/CAM systems available for the fabrication of crown and bridge restorations. Aust Dent J 2011;56(Suppl 1):97-106.

4. Joda T, Bragger U. Time-efficiency analysis of the treatment with monolithic implant crowns in a digital workflow: a randomized controlled trial. Clin Oral Implants Res 2016;27:1401-6.

5. Joda T, Bragger U. Digital vs. conventional implant prosthetic workflows: a cost/time analysis. Clin Oral Implants Res 2015;26:1430-5.

6. Brownstein SA, Murad A, Hunt RJ. Implementation of new technologies in U.S. dental school curricula. J Dent Educ 2015;79(3):259-64.

7. Kattadiyil MT, Jekki R, Goodacre CJ, Baba NZ. Comparison of treatment outcomes in digital and conventional 
complete removable dental prosthesis fabrications in a predoctoral setting. J Prosthet Dent 2015;114:818-25.

8. Reifeis PE, Kirkup ML, Willis LH, Browning WD. Introducing CAD/CAM into a predoctoral dental curriculum: a case study. J Dent Educ 2014;78(10):1432-41.

9. Iacopino AM. The influence of "new science" on dental education: current concepts, trends, and models for the future. J Dent Educ 2007;71(4):450-62.

10. Patel N. Integrating three-dimensional digital technologies for comprehensive implant dentistry. J Am Dent Assoc 2010;141(Suppl 2):20S-24S.

11. Barwacz CA, Avila-Ortiz G, Allareddy V, et al. An overview of U.S. predoctoral dental implant programs and their directors. J Dent Educ 2015;79(3):265-77.

12. Yuzbasioglu E, Kurt H, Turunc R, Bilir H. Comparison of digital and conventional impression techniques: evaluation of patients' perception, treatment comfort, effectiveness, and clinical outcomes. BMC Oral Health 2014;14:10.

13. DiLullo C, McGee P, Kriebel RM. Demystifying the millennial student: a reassessment in measures of character and engagement in professional education. Anat Sci Educ 2011;4:214-26.

14. Evans L, Hanes PJ. Online cultural competency education for millennial dental students. J Dent Educ 2014;78(6):867-75.

15. Afshari FS, Yuan JC, Quimby A, et al. Advanced predoctoral implant program at UIC: description and qualitative analysis. J Dent Educ 2014;78(6):770-8.

16. Lee DJ, Harlow RE, Yuan JC, et al. Three-year clinical outcomes of implant treatments provided at a predoctoral implant program. Int J Prosthod 2011;24:71-6.

17. Yuan JC, Kaste LM, Lee DJ, et al. Dental student perceptions of predoctoral implant education and plans for providing implant treatment. J Dent Educ 2011;75(6):750-60.

18. Grant GT, Campbell SD, Masri RM, Andersen MR. Glossary of digital dental terms: American College of Prosthodontists. J Prosthod 2016;25(Suppl 2):S2-9.

19. Commission on Dental Accreditation. Accreditation standards for dental education programs. Chicago: American Dental Association, 2016.

20. Galhano GA, Pellizzer EP, Mazaro JV. Optical impression systems for CAD-CAM restorations. J Craniofac Surg 2012;23:e575-9.

21. Gallucci GO, Papaspyridakos P, Ashy LM, et al. Clinical accuracy outcomes of closed-tray and open-tray implant impression techniques for partially edentulous patients. Int J Prosthod 2011;24:469-72.

22. Johnson GH, Craig RG. Accuracy of four types of rubber impression materials compared with time of pour and a repeat pour of models. J Prosthet Dent 1985;53:484-90.

23. Faria AC, Rodrigues RC, Macedo AP, et al. Accuracy of stone casts obtained by different impression materials. Braz Oral Res 2008;22:293-8.

24. Michalakis KX, Stratos A, Hirayama H, et al. Delayed setting and hygroscopic linear expansion of three gypsum products used for cast articulation. J Prosthet Dent 2009;102:313-8

25. Millstein PL. Determining the accuracy of gypsum casts made from type IV dental stone. J Oral Rehabil 1992;19:239-43.

26. Karl M, Graef F, Schubinski P, Taylor T. Effect of intraoral scanning on the passivity of fit of implant-supported fixed dental prostheses. Quintessence Int 2012;43:555-62.

27. Seelbach P, Brueckel C, Wostmann B. Accuracy of digital and conventional impression techniques and workflow. Clin Oral Investig 2013;17:1759-64.

28. Guth JF, Keul C, Stimmelmayr M, et al. Accuracy of digital models obtained by direct and indirect data capturing. Clin Oral Investig 2013;17:1201-8.

29. Gjelvold B, Chrcanovic BR, Korduner EK, et al. Intraoral digital impression technique compared to conventional impression technique: a randomized clinical trial. J Prosthod 2016;25:282-7.

30. Boeddinghaus M, Breloer ES, Rehmann P, Wostmann B. Accuracy of single-tooth restorations based on intraoral digital and conventional impressions in patients. Clin Oral Investig 2015;19:2027-34.

31. Joda T, Bragger U. Patient-centered outcomes comparing digital and conventional implant impression procedures: a randomized crossover trial. Clin Oral Implants Res 2016;27(12):e185-9.

32. Lee SJ, Gallucci GO. Digital vs. conventional implant impressions: efficiency outcomes. Clin Oral Implants Res 2013;24:111-5.

33. Wismeijer D, Mans R, van Genuchten M, Reijers HA. Patients' preferences when comparing analogue implant impressions using a polyether impression material versus digital impressions (intraoral scan) of dental implants. Clin Oral Implants Res 2014;25:1113-8.

34. State of industry. Lab Manag Today 2000;16:9-15. 